Brazilian Journal

of Chemical

ISSN 0104-6632

Engineering

Printed in Brazil

www.scielo.br/bjce

Vol. 35, No. 01, pp. 169 - 180, January - March, 2018

(cc) BY

dx.doi.org/10.1590/0104-6632.20180351s20160351

\title{
MODIFICATION OF PALM OIL CRYSTALLIZATION BY PHYTOSTEROL ADDITION AS A TOOL FOR STRUCTURING A LOW SATURATED LIPID BLEND
}

\author{
Monise Helen Masuchi Buscato ${ }^{1}$, Barbara Gallani Zaia ${ }^{2}$, Kamila Ramponi Rodrigues de \\ Godoi $^{2}$, Ana Paula Badan Ribeiro ${ }^{2}$ and Theo Guenter Kieckbusch ${ }^{1}$ \\ ${ }^{1}$ School of Chemical Engineering, University of Campinas, Albert Einstein Avenue, 500 13083-852, \\ Cidade Universitaria Zeferino Vaz, Campinas, Sao Paulo, Brazil \\ ${ }^{2}$ School of Food Engineering, University of Campinas, Brazil
}

(Submitted: May 31, 2016; Revised: November 21, 2016; Accepted: November 29, 2016)

\begin{abstract}
Fat structural modifications promoted by phytosterol addition - a hypocholesterolemic component - to palm oil and a mixture of palm oil and canola oil were evaluated in order to develop fats with reduced saturated fatty acids. Palm oil added with free or esterified phytosterols was investigated in terms of triacylglycerol composition, microstructure, solid fat content, and crystallization behavior before and after chemical interesterification. The addition of $10 \%$ of free phytosterols to samples before interesterification built up a denser crystal fat network structure. After interesterification, the free phytosterols lost their structuring ability and behaved as the esterified form. Free phytosterols were subsequently added to blends of palm oil and canola oil $(50: 50 \mathrm{w} / \mathrm{w} \%)$ at different concentrations. Consistency measurements and microscopic observations confirmed that, at concentrations of 6,8 , and $10 \%$, the free phytosterols upgraded the fat structure forming a strongly cohesive fat crystal network.
\end{abstract}

Keywords: phytosterols; palm oil; canola oil; saturated fatty acids; fat crystal network.

\section{INTRODUCTION}

Oils and fats are raw materials present in the formulation of most processed food and are considered important nutritional constituents. According to current international health organizations, the lipid matrices in food formulations are recommended to contain low levels of saturated fatty acids (low sat) and absence of fatty acids with trans isomers (zero trans), which are associated with increasing cardiovascular diseases (Keys et al., 1965). Along with these nutritional issues, oils and fats should display appropriate structural and sensorial characteristics for the manufacture and for the consumer acceptability of processed food.

According to Haighton (1959), fat blends can be classified by ranges of yield value (YV) as soft, plastic or too hard, a practical parameter used mainly for applications in margarines and shortening. Lipid blends exhibiting yield values between 200 and $800 \mathrm{~g}_{\mathrm{F}} / \mathrm{cm}^{2}$ for example, are characterized as satisfactory plastic and spreadable. For values lower than $100 \mathrm{~g}_{\mathrm{F}} / \mathrm{cm}^{2}$, the material is classified as soft or very soft, not spreadable, and pourable. Thus, in compliance with health organizations recommendations and also according to specific industrial, commercial and product identification needs, new or alternative zero trans and low sat fats should be developed (Pernetti et al., 2007; Rogers, 2009).

Several reviews present innovative materials and advanced techniques for the development of fat structuration aiming the reduction of saturated fatty acids level and the zero trans approach (Bot et al., 2009; Co and Marangoni, 2012; Dassanayake et al., 2011; Pernetti et al., 2007; Rogers, 2009; Siraj et al., 2015). Numerous

\footnotetext{
* Corresponding Author: Monise Helen Masuchi Buscato. E-mail: monise.masuchi@gmail.com. Phone: +55 (19) 997736226
} 
polar and nonpolar additives are being considered as promising structuring agents - also termed oleogelators - of lipid systems such as high-melting triacylglycerols, monoacylglycerols, diacylglycerols, fatty acids, fatty alcohols, waxes, wax esters, ceramides, sorbitan monostearate, sorbitan tristearate, lecithin, phytosterols/ oryzanol, and 12-hydroxystearic acid.

In addition to the application of these different additives to lipid raw materials, interesterification reactions and thermal fractionation are also examples of process implementations, separately or in association, in order to obtain zero trans and low sat fats with industrial applicability (Wassell and Young, 2007).

Most of the scientific developments regarding the applications of phytosterols for crystal network structuration in lipid materials are currently being performed with mixtures of phytosterols (mainly $\beta$-sitosterol) and $\gamma$-oryzanol - the esterified form of $\beta$-sitosterol with ferulic acid (Bot and Agterof, 2006; Bot et al., 2009). Figure 1 presents a structural representation of an esterified and non-esterified $\beta$-sitosterol. According to Bot et al. (2009), molecular aggregation of $\beta$-sitosterol and $\gamma$-oryzanol mixtures forms thin fibrillar building blocks, exhibiting a high specific surface area, enabling them to participate in network connections as an outstanding structuring agent. Ract and Gioielli (2008) evaluated the addition of esterified phytosterols to sunflower oil aiming to customize the consistency of milk fat by chemical interesterification of a mixture of these three components. They observed a decrease in consistency of the interesterified blend at low temperatures and increased hardness at room temperatures. Acevedo and Franchetti (2016) assessed mainly structural properties of blends containing 0,20 and $25 \%(\mathrm{w} / \mathrm{w} \%)$ of free phytosterols $-\beta$-sitosterol or stigmasterol - in soybean oil and fully hydrogenated soybean oil, observing the formation of a co-crystallized system and arise in the melting temperature.

Considering the interesterification reaction of a fat blend containing phytosterols, Ferrari et al. (1997) reported that the chemical structure of the added non-esterified phytosterols was changed after the interesterification process, since the free phytosterol form was transformed into an esterified one.

In addition to the possible uses of phytosterols as fat and oil structuring agents, they also contribute to very important health benefits by lowering the levels of blood cholesterols. Katan et al. (2003), for instance, reported that phytosterols are responsible for the decrease in about $10 \%$ of the LDL cholesterol in the human blood with an average daily intake of about $2.0 \mathrm{~g}$.

In the food industry, phytosterols have been added in healthier margarine formulations, generally in the esterified form, easier to solubilize in lipid materials due to the fatty acid moiety (Belitz et al., 2009).

The crystallization modification effects promoted by

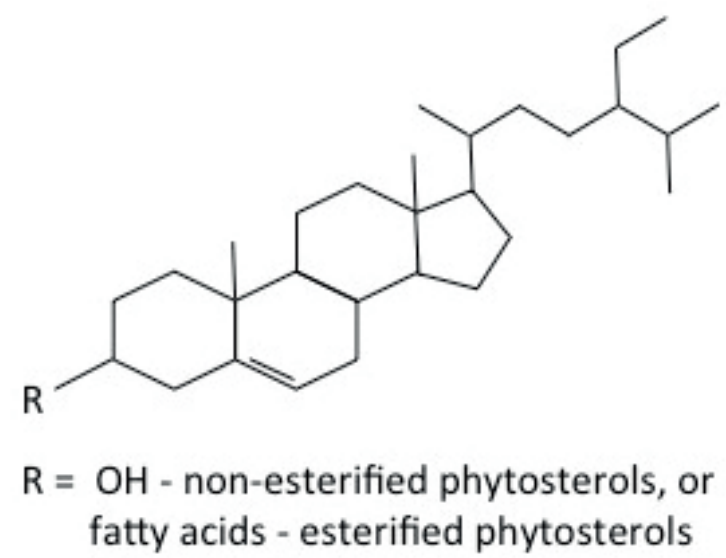

Figure 1. Structural representation of an esterified and non-esterified $\beta$-sitosterol.

the addition of phytosterols (mainly the non-esterified form) to low saturated lipid matrices are still insufficiently investigated.

In this context, this research aimed to evaluate phytosterol additions in the esterified and non-esterified forms as potential modifier agents of the crystal structure of palm oil. The blend was then submitted to interesterification as a possible way to facilitate the incorporation of phytosterols, mainly the non-esterified form, into the lipid structures. After this initial evaluation of the phytosterols incorporation and crystallization ability in the palm oil structure, a low saturated lipid blend $(50 \%$ palm oil and $50 \%$ canola oil) added with non-esterified phytosterols was considered in order to combine the structuring ability of phytosterols and the development of healthier fat blends. The structured samples were evaluated in terms of fatty acid and triacylglycerol compositions, solid fat content, crystallization behavior, consistency, and morphological structure.

\section{MATERIALS AND METHODS}

\section{Materials}

Refined palm oil (PO) was provided by Agropalma (Brazil). Canola oil was purchased at a local market. Free and esterified phytosterols obtained mainly from soya beans were purchased at Cognis (Germany). According to the supplier, the free phytosterol composition was: brasicasterol - $3.6 \%$, campesterol - $26.2 \%$, stigmasterol $14.0 \%$, $\beta$-sitosterol $-47.4 \%$, others $-8.8 \%$; the esterified phytosterols (mainly derived from soybean) composition was: brasicasterol $-2.4 \%$, campesterol - $26.7 \%$, campestanol - $23.0 \%, \beta$-sitosterol - $43.7 \%$, others - $4.2 \%$. Sodium methoxide (95\%) used in the chemical interesterification was purchased from Sigma Aldrich (United States). 


\section{Sample preparation}

The two forms of phytosterols, free (FPh) and esterified (EPh), were added separately to palm oil, obtaining, respectively, the samples named POF and POE with $10 \%(\mathrm{w} / \mathrm{w})$ of the respective phytosterol form in each sample. A blank sample (named PO) with no addition of phytosterols was considered for comparison. The blends were melted at $100^{\circ} \mathrm{C}$ and maintained at this temperature during 10 minutes under constant stirring for complete homogenization and effective incorporation of phytosterols. The three samples - PO, POF and POE were chemically interesterified, originating, respectively, the samples POi, POFi and POEi. In a subsequent study (Section "Crystallization of a 50:50 blend of canola and palm oil, added with free phytosterols"), a blend of canola oil and palm oil (50:50) received 2, 4, 6, 8, and $10 \%$ of free phytosterols prepared as described above, but without chemical interesterification.

\section{Chemical interesterification reaction}

The reaction was carried out in a closed vessel using $100 \mathrm{~g}$ of each sample and $0.4 \%(\mathrm{w} / \mathrm{w})$ of sodium methoxide at $90^{\circ} \mathrm{C}$ under constant stirring $(500 \mathrm{rpm})$ during $20 \mathrm{~min}$, according to optimized conditions described by Grimaldi et al. (2005).

\section{Fatty acid composition}

An Agilent 6850 Series Gas Chromatograph (GC) system (Santa Clara, CA, USA) equipped with a capillary column and flame ionisation detector (FID) was used to obtain fatty acid composition of palm oil and canola oil, according to Hartman and Lago (1973). The fatty acid methyl esters were separated as described by the AOCS Method Ce 2-66 (AOCS, 2009), using a $60 \mathrm{~m}$ length DB-23 Agilent capillary column (Santa Clara, CA, USA) (50\% cyanopropyl-methylpolysiloxane) with internal diameter of $0.25 \mathrm{~mm}$ and coated with a $0.25 \mu \mathrm{m}$ film. The operating conditions for the oven temperature program were $110^{\circ} \mathrm{C}$ for $5 \mathrm{~min}$, followed by heating to $215^{\circ} \mathrm{C}$ at a rate of $5^{\circ} \mathrm{C} / \mathrm{min}$ and holding at $215^{\circ} \mathrm{C}$ for $24 \mathrm{~min}$. Other running conditions: detector temperature: $280^{\circ} \mathrm{C}$, injector temperature: $250^{\circ} \mathrm{C}$; helium used as stripping gas; split ratio of 1:50; and $1.0 \mu \mathrm{L}$ injection volume. Qualitative composition was determined by comparing peak retention times with the respective standards for fatty acids. Samples were analysed in duplicate and the values reported are means of two injections.

\section{Triacylglycerol composition}

Triacylglycerol composition determination was performed in triplicate using the same capillary GC CGC Agilent 6850 Series GC System (Santa Clara, CA, USA), with a DB-17 HT Agilent capillary column (Santa Clara, CA,
USA) (50\%-phenyl-methylpolysiloxane) $15 \mathrm{~m}$ in length and $0.25 \mathrm{~mm}$ of internal diameter, coated with a $0.15 \mu \mathrm{m}$ film. The operating conditions were: 1:100 split injection ratio; initial column temperature of $250^{\circ} \mathrm{C}$, heated up to $350^{\circ} \mathrm{C}$ at $5^{\circ} \mathrm{C} / \mathrm{min}$; helium as stripping gas at $1.0 \mathrm{~mL} / \mathrm{min}$; injector temperature of $360^{\circ} \mathrm{C}$; detector temperature of $375^{\circ} \mathrm{C} ; 1.0$ $\mu \mathrm{L}$ injection volume and sample concentration of $10 \mathrm{mg} / \mathrm{mL}$ in tetrahydrofuran. The triacylglycerols were identified by comparing retention time with standard samples and were quantified based on relative peak area (Antoniosi Filho et al., 1995). The results are expressed as the mean of three replicates followed by standard deviations.

\section{Solid fat content}

Solid fat content (SFC) was measured using a nuclear magnetic resonance spectrometer Bruker pc 120 Minispec (Silberstreifen, Rheinstetten, Germany) according to AOCS direct method Cd 16b-93 (AOCS, 2009). Sample preparation for the measurement was the following: melting at $100^{\circ} \mathrm{C}$ for $15 \mathrm{~min}$, conditioned at $60^{\circ} \mathrm{C}$ during $5 \mathrm{~min}$, chilled to $0^{\circ} \mathrm{C}$ for $90 \mathrm{~min}$, and then kept at each measurement temperature $(10,15,20,25,30$, 35 and $40^{\circ} \mathrm{C}$ ) during $30 \mathrm{~min}$ in a high precision dry bath (TCON 2000, Duratech, Carmel, IN, USA), prior to SFC measurements. The results are expressed as the mean of three determinations.

\section{Crystallization behavior}

Thermal behavior was determined with a differential scanning calorimetry (DSC), model Q2000 (TA Instruments, USA) according to the AOCS Method $\mathrm{Cj}$ 1-94 (AOCS, 2009). Melted samples were weighted (approximately $10 \mathrm{mg}$ ) in aluminum pans and hermetically sealed with covers. An empty sealed aluminum pan was used as reference and the equipment was previously calibrated using indium. The operation conditions were: initial temperature of $140^{\circ} \mathrm{C}$ maintained for $5 \mathrm{~min}$, cooling to $-80^{\circ} \mathrm{C}$ at a rate of $10^{\circ} \mathrm{C} / \mathrm{min}$, and maintained at $-80^{\circ} \mathrm{C}$ for $5 \mathrm{~min}$. The crystallization onset temperature $\left(\mathrm{T}_{\text {onset }}\right)$ of each sample was calculated by Advantage Software (TA Instruments, USA) through linear peak integration. The results are expressed as the mean of three determinations followed by the respective standard deviation.

\section{Consistency}

Consistencies were determined by the texture analyzer TA-XT Plus (Stable Micro Systems, Surrey, UK). Initially the samples were heated to $100^{\circ} \mathrm{C}$ for complete melting of the fat crystals, then conditioned in $50 \mathrm{~mL}$-incubators at $5^{\circ} \mathrm{C}$ for $24 \mathrm{~h}$, for fat crystallization and, subsequently conditioned for $24 \mathrm{~h}$ at each of the pre-determined temperatures $\left(15,20\right.$ and $\left.25^{\circ} \mathrm{C}\right)$. The probe was a Plexiglas ${ }^{\circledR}$ 
cone with non-truncated tip angle of $45^{\circ}$. The penetration depth applied was $10 \mathrm{~mm}$ with probe velocity of $2 \mathrm{~mm} / \mathrm{s}$. The compression force obtained is given in gram force $\left(\mathrm{g}_{\mathrm{F}}\right)$ (Campos, 2007). According to Haighton (1959), the compression force is converted to yield value (YV) by the following equation (Eq. 1):

$$
Y V=\frac{K W}{P^{1.6}}
$$

where $\mathrm{YV}$ is yield value, in $\mathrm{g}_{\mathrm{F}} / \mathrm{cm}^{2} ; \mathrm{K}$ is the constant that is dependent on the cone angle. For a cone with $45^{\circ}$ the value is 4700 ; $\mathrm{W}$ is compression force, in $\mathrm{g}_{\mathrm{F}}$; $\mathrm{p}$ is penetration depth, in units of $0.1 \mathrm{~mm}$. The samples were analysed in quadruplicate and the results are expressed as the means of the replicates.

\section{Crystal morphology}

Images were acquired by a polarized Light Microscope (Olympus, model BX 51, USA), coupled to a digital video camera (Media Cybernetics, USA). Samples were first melted at $100^{\circ} \mathrm{C}$ and then approximately 1 drop of each sample was placed on a pre-heated glass slide and covered with a coverslip. Slides were incubated for $3 \mathrm{~h}$ at $25^{\circ} \mathrm{C}$ and then placed on the heated stage (Mettler Toledo, FP82 Microscope Hot Stage, USA) at the same temperature $\left(25^{\circ} \mathrm{C}\right)$ for image acquisition. The images were captured by the software Image Pro-Plus version 7.0 (Media Cybernetics, USA), under polarized light and amplification of 40 times. Randomly, three visual areas of each slide were chosen and focused for a qualitative evaluation of the fat crystal network.

\section{Visual observations}

Aliquots of $35 \mathrm{~mL}$ of the samples 50:50 PO:CO added with $2,4,6,8$, and $10 \%$ of non-esterified phytosterols were placed in a $70 \mathrm{~mL}$-glass-flasks with caps. First, the samples were allowed to melt at $100^{\circ} \mathrm{C}$, and then maintained at $5^{\circ} \mathrm{C}$ during $24 \mathrm{~h}$ to crystallize, and then stabilized at $25^{\circ} \mathrm{C}$ for another $24 \mathrm{~h}$. After this stabilization period, the flasks were inverted and exposed at oscillating room temperature between 25 and $30^{\circ} \mathrm{C}$ during 30 days.

Images were taken with a digital camera after 1 minute, 24 hours, and 30 days of the inversion of the flasks.

\section{Statistical Analysis}

Yield value $\left(\mathrm{g}_{\mathrm{F}} / \mathrm{cm}^{2}\right)$ and crystallization onset temperature $\left({ }^{\circ} \mathrm{C}\right)$ were statistically analyzed by one-way analysis of variance (ANOVA) using STATISTICA V.8 software (StatSoft Inc., USA). Tukey's post hoc test was applied for statistical comparison among the means with a significance level of $5 \%(p<0.05)$.

\section{RESULTS AND DISCUSSION}

The knowledge of the fatty acid composition is useful for anticipating the lipid materials characteristics and their physico-chemical behavior. For the development of fats with reduced saturated fatty acids content, this insight is of fundamental importance. Table 1 presents the fatty acid composition and the total amount of saturated and unsaturated fatty acids of palm oil, canola oil and a blend made of $50 \%(\mathrm{w} / \mathrm{w} \%)$ of $\mathrm{PO}$ and $\mathrm{CO}$, named PO:CO 50:50.

The fatty acid composition of palm oil presented approximately $50 \%$ of saturated fatty acids and $50 \%$ of unsaturated fatty acids, as usually reported in the literature (Basiron, 2005). This distinguishing composition of palm oil is the main factor that accounts for the wide usage of palm oil in different food applications and also as a raw material for obtaining other lipid materials such as palm oil stearin and olein by fractionation processes.

Table 1. Fatty acids composition (\%) of palm oil (PO), canola oil (CO) and the blend of 50:50 (w/w\%) of PO:CO.

\begin{tabular}{lcccc}
\hline Fatty Acids (\%) & & $\begin{array}{c}\text { Palm } \\
\text { oil } \\
(\mathrm{PO})\end{array}$ & $\begin{array}{c}\text { Canola } \\
\text { Oil } \\
(\mathrm{CO})\end{array}$ & $\begin{array}{c}\text { PO:CO } \\
50: 50 \\
(\mathrm{w} / \mathrm{w} \%)\end{array}$ \\
\hline Lauric acid & $\mathrm{C} 12: 0$ & 0.6 & 0.0 & 0.3 \\
Myristic acid & $\mathrm{C} 14: 0$ & 0.9 & 0.1 & 0.5 \\
Palmitic acid & $\mathrm{C} 16: 0$ & 40.5 & 5.0 & 22.8 \\
Palmitoleic acid & $\mathrm{C} 16: 1$ & 0.1 & 0.3 & 0.2 \\
Margaric acid & $\mathrm{C} 17: 0$ & 0.1 & 0.1 & 0.1 \\
Stearic acid & $\mathrm{C} 18: 0$ & 4.8 & 2.7 & 3.8 \\
Oleic acid & $\mathrm{C} 18: 1$ & 43.3 & 61.5 & 52.4 \\
Linoleic acid & $\mathrm{C} 18: 2$ & 8.7 & 19.0 & 13.8 \\
Linolenic acid & $\mathrm{C} 18: 3$ & 0.2 & 8.6 & 4.4 \\
Araquidic acid & $\mathrm{C} 20: 0$ & 0.4 & 0.8 & 0.6 \\
Gadoleic acid & $\mathrm{C} 20: 1$ & 0.2 & 1.1 & 0.6 \\
Behenic acid & $\mathrm{C} 22: 0$ & 0.1 & 0.5 & 0.3 \\
Erucic acid & $\mathrm{C} 22: 1$ & 0.0 & 0.1 & 0.1 \\
Lignoceric acid & $\mathrm{C} 24: 0$ & 0.1 & 0.2 & 0.2 \\
\hline$\Sigma$ Saturated fatty acids & 47.5 & 9.4 & 28.5 \\
$\Sigma$ Unsaturated fatty acids & 52.5 & 90.6 & 71.5 \\
\hline
\end{tabular}

Canola oil composition presents $9.4 \%$ of saturated fatty acids and, as also observed for the palm oil sample, contains no trans fatty acids. Due to the high amount of unsaturated fatty acids, canola oil can be added to lipid formulations to effectively decrease the relative content of saturated fatty acids. In this context, the 50:50 sample of canola oil and palm oil induced a reduction of $40 \%$ of the saturated fatty acids originally in palm oil. 


\section{Crystallization of palm oil added with phytosterols: effect of chemical interesterification}

In order to evaluate the potential modification action on the palm oil crystal structure promoted by phytosterols, samples of pure palm oil received $10 \%$ of free phytosterols $(\mathrm{FPh})$ and $10 \%$ of the esterified form (EPh). The control sample PO (palm oil with no phytosterol addition) and the other two samples POE (palm oil added with EP) and POF (palm oil added with $\mathrm{FPh}$ ) were chemically interesterified and the respective interesterified samples POi, POEi and POFi were obtained.

\section{Triacylglycerol composition}

To characterize the chemical changes in the lipid systems induced by the interesterification reaction as well as triggered by the phytosterol addition, the samples before (PO, POE and POF) and after (POi, POEi and POFi) the interesterification were evaluated in terms of triacylglycerol composition, solid fat content, crystallization behavior, and crystal morphology.

The triacylglycerol compositions, determined by gas chromatography of the samples before and after the chemical interesterification reaction, are listed in Table 2.

The triacylglycerol compositions shown in Table 2 indicate slight alterations between the $\mathrm{PO}$ and $\mathrm{POi}$ samples, especially in the amounts of PLP, POO and PLO triacylglycerols. This was expected since the reaction was performed using only a single natural lipid material - palm oil. Larger differences between the triacylglycerol compositions of the initial and interesterified samples can be found when the lipid materials are physically different, such as a liquid oil and a fully hydrogenated fat.

In samples added with esterified and non-esterified phytosterols before (POE and POF) and after (POEi and POFi) the chemical interesterification reaction, the triacylglycerol compositions indicate apparent changes in the POO triacylglycerol content. However, proper identification of the different triacylglycerols in the four samples was impaired by the presence of peaks related to the phytosterols. The 8 to $11 \%$ unidentified content of triacylglycerols observed in the POFi and POEi is probably related to the presence of free and/or esterified phytosterols in these samples.

\section{Solid fat content}

In Figure 2, the solid fat content (SFC, in \%) is shown at temperatures of $10,15,20,25,30,35$, and $40^{\circ} \mathrm{C}$. All samples showed some difference in solid fat content at most measurement temperatures before and after the reaction. At lower temperatures $-10,15$ and $20^{\circ} \mathrm{C}$ - larger differences can be observed. At $10^{\circ} \mathrm{C}$, for instance, the samples can be divided in two distinct groups: the first group presenting an average of $48 \%$ of SFC, and the second, approximately $40 \%$ of SFC. The first group - showing $10 \%$ more solid fat content than the other - includes PO, POi and POF samples. The group with lower solid fat content is composed by POE, POEi, and POFi. At higher measured temperatures such as 25,30 , and $35^{\circ} \mathrm{C}$, the curves indicate that the sample POF presents the highest content of solid fat: approximately $2 \%$ higher than the other samples.

The solid fat content curves suggest that the addition of esterified phytosterols decreased the solid fat content of palm oil, hampering the formation of the crystalline organization, probably due to their chemical structure which contain esterified fatty acids. It is known that the presence of fatty acids in plant sterol molecules favors solubility when added in lipid materials, due to the similarity between the molecular structures (lipids and esterified phytosterols).

Table 2. Triacylglycerol composition (TAG, in $\% \mathrm{w} / \mathrm{w}$ ) of palm oil, palm oil added with $10 \%$ of esterified phytosterols and $10 \%$ of non-esterified phytosterols, before (PO, POE, POF) and after (POi, POEi, POFi) the chemical interesterification reaction.

\begin{tabular}{|c|c|c|c|c|c|c|c|}
\hline $\mathrm{CN}$ & TAG (\%) & PO & POi & POE & POEi & POF & POFi \\
\hline $\mathrm{C} 46$ & PPM & $0.4 \pm 0.1$ & $0.5 \pm 0.0$ & $0.4 \pm 0.1$ & $0.5 \pm 0.1$ & $0.4 \pm 0.1$ & $1.0 \pm 0.2$ \\
\hline $\mathrm{C} 48$ & PPP & $7.9 \pm 0.3$ & $8.0 \pm 0.1$ & $7.9 \pm 0.3$ & $10.3 \pm 0.2$ & $7.9 \pm 0.3$ & $7.2 \pm 0.1$ \\
\hline \multirow{3}{*}{ C50 } & PPS/POP* & $32.8 \pm 0.3$ & $33.2 \pm 0.1$ & $32.8 \pm 0.3$ & $30.7 \pm 0.2$ & $32.8 \pm 0.3$ & $30.3 \pm 0.3$ \\
\hline & PLP & $7.3 \pm 0.3$ & $6.6 \pm 0.3$ & $7.3 \pm 0.3$ & $6.2 \pm 0.3$ & $7.3 \pm 0.3$ & $6.2 \pm 0.2$ \\
\hline & POS/POO* & $31.8 \pm 0.4$ & $30.5 \pm 0.4$ & $31.8 \pm 0.4$ & $28.6 \pm 0.6$ & $31.8 \pm 0.4$ & $28.8 \pm 0.4$ \\
\hline \multirow[t]{3}{*}{ C52 } & PLO & $7.5 \pm 0.2$ & $6.4 \pm 0.1$ & $7.5 \pm 0.2$ & $6.6 \pm 0.1$ & $7.5 \pm 0.2$ & $6.0 \pm 0.0$ \\
\hline & PLL & $1.8 \pm 0.3$ & $2.0 \pm 0.2$ & $1.8 \pm 0.3$ & $1.4 \pm 0.5$ & $1.8 \pm 0.3$ & $1.4 \pm 0.1$ \\
\hline & SOO & $2.7 \pm 0.0$ & $2.5 \pm 0.1$ & $2.7 \pm 0.0$ & $2.3 \pm 0.1$ & $2.7 \pm 0.0$ & $2.5 \pm 0.1$ \\
\hline \multirow[t]{3}{*}{ C54 } & OOO & $4.7 \pm 0.1$ & $4.4 \pm 0.2$ & $4.7 \pm 0.1$ & $4.2 \pm 0.1$ & $4.7 \pm 0.1$ & $4.3 \pm 0.1$ \\
\hline & OLO & $1.1 \pm 0.1$ & $1.1 \pm 0.0$ & $1.1 \pm 0.1$ & $0.9 \pm 0.1$ & $1.1 \pm 0.1$ & $0.9 \pm 0.1$ \\
\hline & Others & $2.0 \pm 0.6$ & $4.9 \pm 0.5$ & $2.0 \pm 0.6$ & $8.2 \pm 0.3$ & $2.0 \pm 0.6$ & $11.4 \pm 0.5$ \\
\hline
\end{tabular}

CN: carbon number; i: interesterified samples; P: palmitic acid; M: myristic acid; S: stearic acid; O: oleic acid; L: linoleic acid; Others: non-identified diacylglycerols and/or triacylglycerols and/or phytosterols; ${ }^{*}$ Major triacylglycerol among the listed ones. 


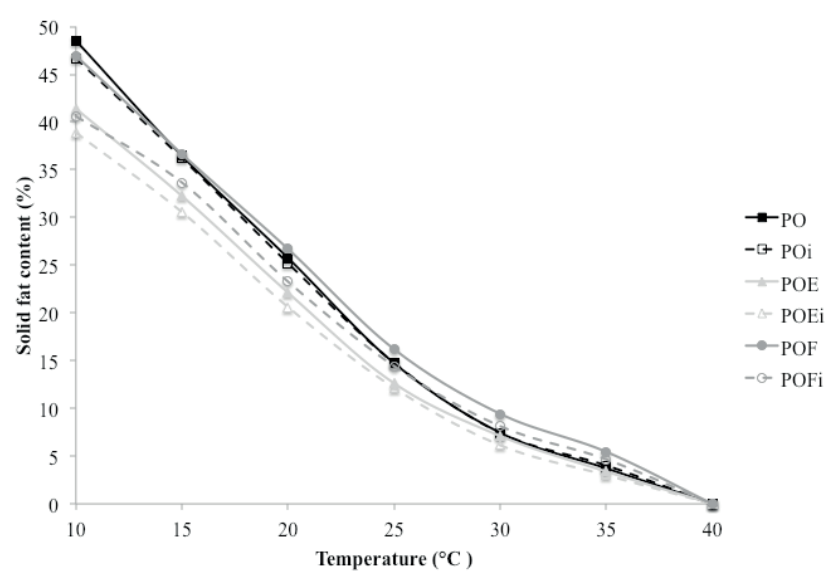

Figure 2. Solid fat content (in \%) of palm oil, palm oil added with $10 \%$ of esterified phytosterols and $10 \%$ of non-esterified phytosterols, before (PO, POE, POF) and after (POi, POEi, POFi) the chemical interesterification, measured at different temperatures $\left({ }^{\circ} \mathrm{C}\right)$

These components can organize themselves in a simpler way compared to the triacylglycerols in the lipid mixture, not favoring the creation of a different crystal network (Belitz et al., 2009; Rodrigues et al., 2007). One of the main objectives of the present research of promoting the increment of solid fat content was not achieved by the addition of esterified phytosterols in palm oil. Furthermore, the simple addition of free phytosterols, i.e. sterols not esterified with fatty acids, to palm oil (POF) resulted in an increase in the solids content of the sample. After the interesterification (POFi), however, the palm oil sample with added free phytosterols showed reduced solids content compared to the sample before the reaction (POF). A similar trend was found by Ferrari et al. (1997), who confirmed that free phytosterols have their chemical structure changed after the interesterification process, since the non-esterified forms are transformed in esterified phytosterols during this reaction. On the other hand, POFi exhibited higher SFC values at all measured temperatures compared to POEi, suggesting that not all free phytosterols were esterified during the chemical interesterification reaction.

\section{Crystal morphology by microscopic observation}

The crystal network morphology of the pure palm oil sample, with free phytosterols and esterified phytosterols before (PO, POE and POF) and after (POi, POEi and POFi) the chemical interesterification was observed under polarized light microscopy, after submission to isothermal crystallization during $3 \mathrm{~h}$ at $25^{\circ} \mathrm{C}$. The images, obtained under a 40-fold magnification, are presented in Figure 3.

Palm oil crystalline elements showed an average diameter of approximately $50 \mu \mathrm{m}$, distributed as a noncohesive lipid network. The same morphology can be observed in POi, POE and POEi samples. However the micrographs of these two last samples added with esterified phytosterols show higher amount of liquid oil, represented by the black background in the images, and also larger features, in a more dispersed way and less densely compacted.

The morphology of the crystals of palm oil added with free phytosterol and not yet submitted to the interesterification reaction (POF) presented a completely different crystal network compared to the other samples. The POF image showed a network of smaller tightly packed crystals, and larger fibrillar crystals trapped within this frame can also be observed, which characterizes the typical morphology described in the literature for non-esterified phytosterols (Bot et al., 2009; Rogers, 2009). The microstructural differences observed among the samples added with free and esterified phytosterols can be attributed to a self-assembly mechanism of the free phytosterol forms added to the palm oil sample, as described by Dassanayake et al.(2011).

The POFi image displayed crystal morphology analogous to the POE and POEi samples (Figure 3), repeating the trend found in the solid fat content results and supporting the assumption that the free phytosterol chemical structure was modified by esterification of their molecules during the interesterification reaction.

\section{Crystallization behavior by DSC}

The crystallization behaviors of free phytosterols $(\mathrm{FPh})$ and esterified phytosterols (EPh) were determined by DSC technique and the profiles obtained are presented in Figure 4. The output indicated that both have distinct behavior in terms of crystallization onset temperatures. The EPh's onset of crystallization occurs at approximately $23^{\circ} \mathrm{C}$, in the region of the lipid phase change temperature, while in $\mathrm{FPh}$, this parameter is around $125^{\circ} \mathrm{C}$. Therefore, the incorporation of esterified phytosterols into lipid materials should proceed smoothly, due to similarities in crystallization temperatures. The opposite behavior is expected for the incorporation of free phytosterols and it is known that they are poorly soluble in the fat phase (Belitz et al., 2009).The dissimilar structure and the polar characteristics of $\mathrm{FPh}$, however, can favor the formation of a new fat crystal network. When a uniform blend of non-esterified phytosterols with lipid material at high temperatures is cooled, FPh solidifies first due to its polar and thermal characteristics and starts to self-assemble in fibrillar crystals (Bot et al., 2009; Dassanayake et al., 2011; Rogers, 2009), forming a specific frame. At lower temperatures, the triacylglycerols will crystallize, and the crystals, in turn, could be tightly trapped in the FPhtriacylglycerol network.

The DSC crystallization behavior of pure palm oil and samples added with $10 \%$ of each phytosterol are presented in Figure 5. An effective incorporation of an additive into the lipid matrix assumes that the crystallization events profiles obtained by DSC do not present isolated peaks, 


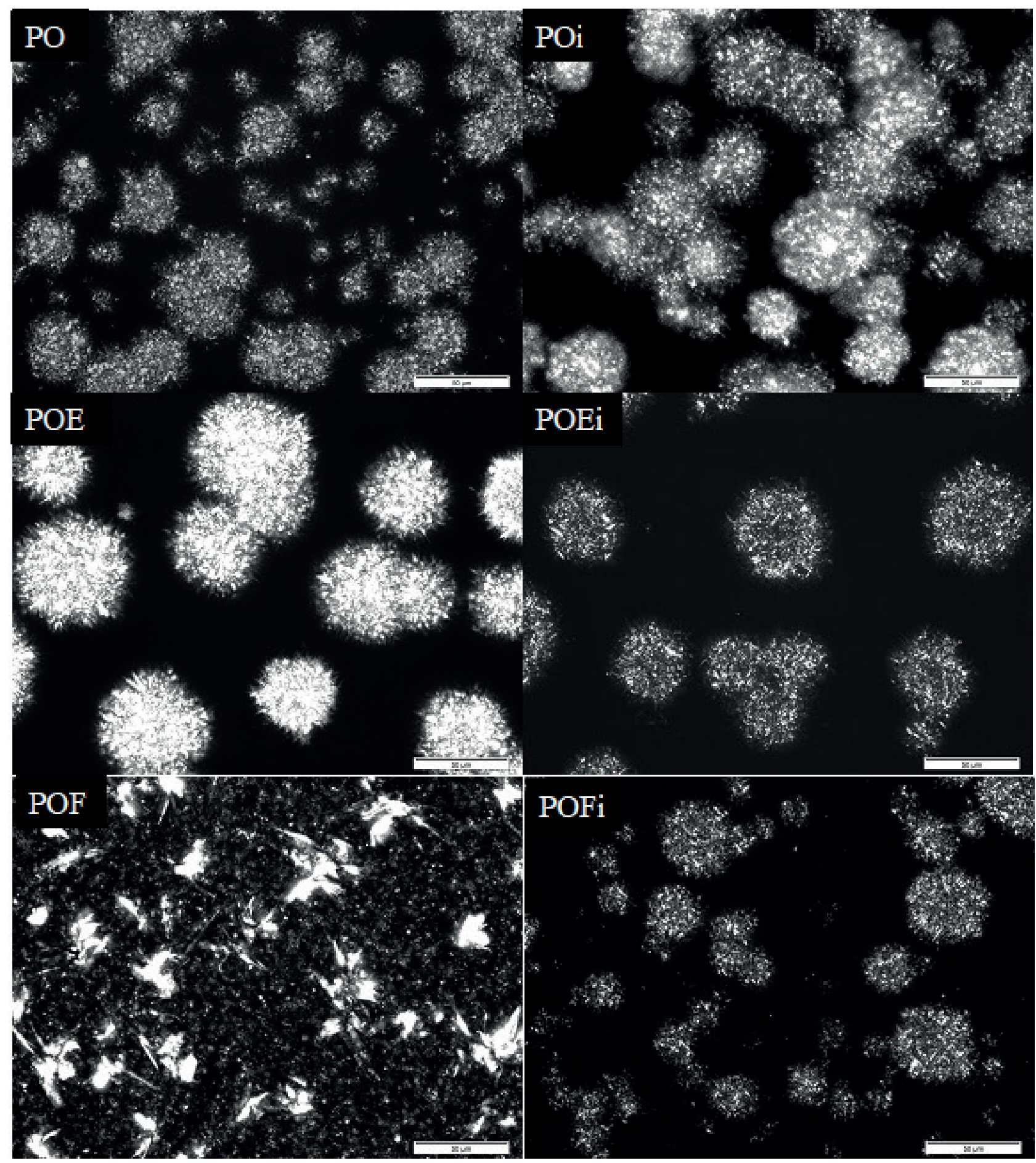

Figure 3. Polarized light microscopy images of palm oil, palm oil added with $10 \%$ of esterified phytosterols and $10 \%$ of non-esterified phytosterols, before (PO, POE, POF) and after (POi, POEi, POFi) the chemical interesterification reaction. The images were taken after $3 \mathrm{~h}$ isothermal crystallization at $25^{\circ} \mathrm{C}$ and the scale bars represent $50 \mu \mathrm{m}$

credited to the pure, isolated component. For instance, an isolated peak around $125^{\circ} \mathrm{C}$ in samples added with $\mathrm{FPh}$ would appear if this component was not effectively incorporated into the lipid material.

By comparison between Figure 4 and 5, no peak in the same crystallization temperature range of pure $\mathrm{FPh}$ was detected, suggesting that the free phytosterol was effectively incorporated into the palm oil. However, the crystallization peak of the pure material could be observed at a smaller cooling rate. On the other hand, it is unreasonable to discuss the effect on the peak related to the pure $\mathrm{EPh}$ due to the presence of other peaks around $20^{\circ} \mathrm{C}$ related to palm oil. 
However, the incorporation of esterified phytosterols to lipid materials is facilitated by their chemical structure similarities and is reported to be easily dispersed in fat systems, like spreads (Belitz et al., 2009).

The crystallization onset temperatures $\left(\mathrm{T}_{\text {onset }},{ }^{\circ} \mathrm{C}\right)$ of each sample, before and after the chemical interesterification, were determined through inspection of the crystallization profiles and their mean values and standard deviations are shown in Table 3.

Two main peaks - termed Peak 2 and Peak 3 in Table 3 - can be observed in all samples, as expected for palm oil crystallization profile by DSC (Basiron, 2005). These two peaks stand for the two main triacylglycerol groups in palm oil: disaturated (represented mainly by POP) and diunsaturated (mainly POO). Palm oil before the interesterification and with no phytosterol additions shows a crystallization onset temperature approximately at $19.4^{\circ} \mathrm{C}$ for the disaturated triacylglycerols, whilst for the diunsaturated ones, it is near $4.8^{\circ} \mathrm{C}$.

Compared to the value of pure palm oil, the crystallization onset temperatures (Peak 2) after the addition of esterified phytosterols and without being interesterified decreased about two degrees. However, after the chemical interesterification, all the samples showed similar temperatures at the beginning of the crystallization.

In general, palm oil added with non-esterified phytosterols presented the most altered crystallization profile among the samples before the interesterification reaction. A third peak with the highest crystallization onset temperature, close to $47^{\circ} \mathrm{C}$, became apparent in the POF sample. This peak suggests that a different crystalline structure with modified crystallization parameters emerged as the result of the free phytosterols addition, before the interesterification reaction. Although the incorporation of non-esterified phytosterols was facilitated after the chemical interesterification reaction, the $\mathrm{FPh}$ probably turns to the esterified forms and its innovative crystallization ability vanished. This behavior, again, resembles the trends found in solid fat content and the microstructure observation for

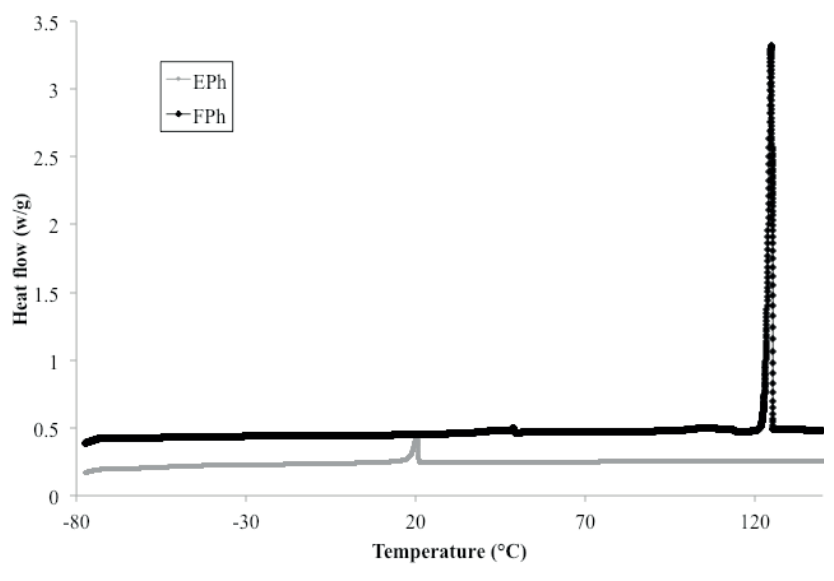

Figure 4. Crystallization profile of free phytosterols $(\mathrm{FPh})$ and esterified phytosterols (EPh). Positive values for heat flow represent exothermic reactions

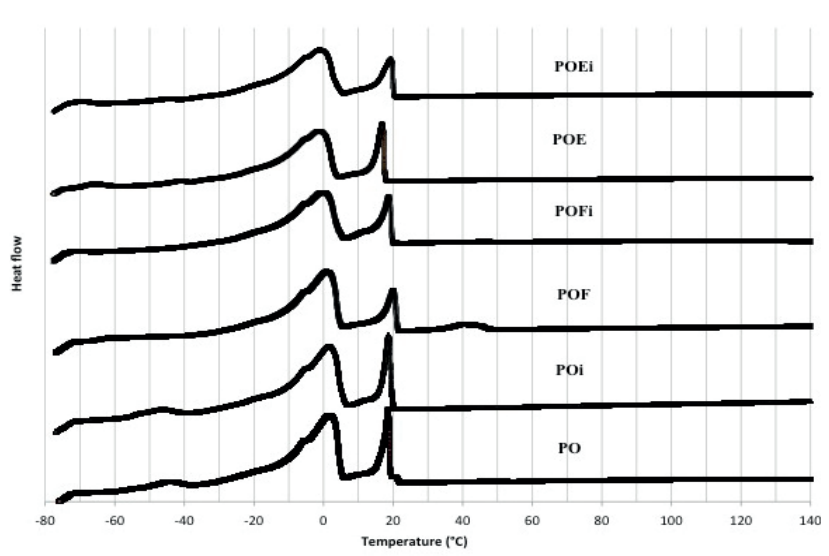

Figure 5. Crystallization profile of palm oil, palm oil added with $10 \%$ of esterified phytosterols, and non-esterified phytosterols before (PO, POE, POF) and after (POi, POEi, POFi) chemical interesterification reaction. Positive values for heat flow represent exothermic reactions

the sample added with non-esterified phytosterols and not interesterified. Consequently, a possible direct application

Table 3. Crystallization onset temperature $\left(\mathrm{T}_{\text {onset}},{ }^{\circ} \mathrm{C}\right)$ of the peaks obtained from the DSC crystallization profile for palm oil, palm oil added with esterified phytosterols and with non-esterified phytosterols before (PO, POE, POF) and after (POi, POEi, POFi) chemical interesterification reaction.

\begin{tabular}{lccc}
\hline & & $\mathbf{T}_{\text {onset }}\left({ }^{\circ} \mathrm{C}\right)$ & \\
Sample & Peak 1 & Peak 2 & Peak 3 \\
\hline PO & - & $19.44 \pm 0.20^{\mathrm{a}}$ & $4.83 \pm 1.12^{\mathrm{a}}$ \\
POi & - & $19.75 \pm 0.62^{\mathrm{a}}$ & $5.69 \pm 0.84^{\mathrm{a}}$ \\
POF & $47.39 \pm 0.51^{\mathrm{a}}$ & $20.78 \pm 0.55^{\mathrm{a}}$ & $4.24 \pm 0.80^{\mathrm{a}}$ \\
POFi & - & $20.07 \pm 0.29^{\mathrm{a}}$ & $4.83 \pm 0.80^{\mathrm{a}}$ \\
POE & - & $17.39 \pm 0.45^{\mathrm{b}}$ & $3.23 \pm 0.67^{\mathrm{a}}$ \\
POEi & - & $19.76 \pm 0.55^{\mathrm{a}}$ & $3.96 \pm 1.51^{\mathrm{a}}$ \\
\hline
\end{tabular}

Same superscript letters in the same column indicate that there are no significant differences between the means evaluated by Tukey's test $(p<0.05)$ 
of free phytosterols for the development of structured fat products with reduced saturated fatty acids can be achieved due to the increase in the solid fat content associated with a denser packed crystal morphology, as presented in the following section.

\section{Crystallization of a 50:50 blend of canola and palm oil, added with free phytosterols}

As seen in the former experiments, adding nonesterified phytosterols to palm oil generated a denser and more homogeneous crystal network. This effect can be attributed to the polar characteristics of non-esterified phytosterols and their difficulties in solubilising in lipid media. Tests indicate that, after adding free phytosterols to palm oil at $100^{\circ} \mathrm{C}$, under constant stirring, a turbid solution is formed due to the polar characteristics of $\mathrm{FPh}$ molecules. If the solution temperature is gradually decreased below $20^{\circ} \mathrm{C}$, under continuing stirring, the $\mathrm{FPh}$ molecules become less compatible with the lipid phase and they will self-assemble in a fibrillar structure forming a continuous network (Bot and Agterof, 2006; Rogers, 2009), generating together with the higher melting triacylglycerols of the sample the framework for the crystallization of the palm oil structure. The remaining liquid lipid phase as well as the lipid crystals are trapped inside this structure. On the other hand, when added to low saturated lipid media, like pure canola oil, a two-phase system is immediately formed and the phytosterol phase settles at the bottom of the mixture, blocking the FPh ability to modify the crystal structuration. Thus, this mechanism suggests that non-esterified phytosterols can only form a denser network when added to samples containing certain amounts of saturated fatty acids, and not those containing only unsaturated ones.

In order to seek a compromise between the structuring action of free phytosterols in palm oil and the shortcomings of low saturated fat systems, a blend denominated PO:CO 50:50 was prepared and its fatty acid profile was presented in Table 1 . The data indicate $40 \%$ less saturated fatty acids content compared to pure palm oil. Five different concentrations - 2, 4, 6, 8, and 10\% (in $\mathrm{w} / \mathrm{w} \%$ ) - of non-esterified phytosterols ( $\mathrm{FPh})$ were added to this lipid system. For comparative purposes, a sample with no phytosterol addition was evaluated together with the structured blends. Samples were evaluated by visual observation, consistency, and crystal morphology.

\section{Visual observation}

In order to acknowledge a qualitative perception of the crystal network formation, Figure 6 shows the images taken of the inverted sample flasks added with free phytosterols $(0,2,4,6,8$, and $10 \%)$ at $1 \mathrm{~min}, 24 \mathrm{~h}$ and 30 days after flask inversion. Immediately after the inversion, only the sample with no addition of free phytosterols decanted, indicating that a fluid lipid blend shaped by a soft crystal network had been formed during the temperature protocol period. After $24 \mathrm{~h}$ at room temperature, the samples added with 2 and $4 \%$ of free phytosterols lost their cohesive crystal structure and also decanted, probably due to the oscillating temperature effects. The additions of 6,8 , and $10 \%$ of non-esterified phytosterols to the palm and canola oil blend were able to assemble a tightly interconnected crystal network, establishing a stable structure, even after 30 days under oscillating room temperature. However, only samples added with 8 and $10 \%$ of free phytosterols showed no liquid oil exudation during the total period of observation.

\section{Consistency}

The consistencies of the samples were determined with a texture analyzer. Figure 7 shows the consistency expressed in yield value $\left(\mathrm{g}_{\mathrm{F}} / \mathrm{cm}^{2}\right)$ for PO:CO 50:50 samples added with $0,2,4,6,8$, and $10 \%$ of free phytosterols $(\mathrm{FPh})$, measured at 15,20 , and $25^{\circ} \mathrm{C}$. A glance at Figure 7 confirms the substantial action of free-phytosterols as a structure forming component, at all temperatures, but mainly at $15^{\circ} \mathrm{C}$. At this temperature, the increase in consistency is linear with the phytosterol concentration.

The yield values presented in Figure 7 indicated that all the samples showed higher consistency at $15^{\circ} \mathrm{C}$. However, only the samples added with 6,8 , and $10 \%$ of FPh showed YV greater than $200 \mathrm{~g}_{\mathrm{F}} / \mathrm{cm}^{2}$ and, therefore, are classified as plastic materials at this temperature (Haighton, 1959). These three samples belong to the group that presented self-stable structure in the visual observation test at $25^{\circ} \mathrm{C}$, mentioned above. However, considering the $\mathrm{YV}$ measured at $25^{\circ} \mathrm{C}$, all samples can be classified as very soft and pourable, according to Haighton (1959).

\section{Crystal morphology by microscopic observation}

The fat crystals formed after isothermal crystallization at $25^{\circ} \mathrm{C}$, for $3 \mathrm{~h}$ in the lipid blend added with free phytosterols were observed under polarized light microscope. The micrographs are presented in Figure 8.

The addition of canola oil to palm oil (PO:CO 50:50) increased the liquid oil fraction, recognizable by the dominant black background in the micrographs. By gradual addition of free phytosterols, mainly at concentrations higher than $4 \%$, a crystal network with higher number of small crystals was formed. The presence of tightly structured small crystals favors the formation of a denser packed network, exhibiting higher consistency, as confirmed by the yield value results. Particularly in the micrograph of PO:CO 50:50 added with 10\% of free phytosterols, besides the formation of a more cohesive crystal structure, crystals featuring larger diameter can also be observed, attributable to free phytosterol crystalline structure. 


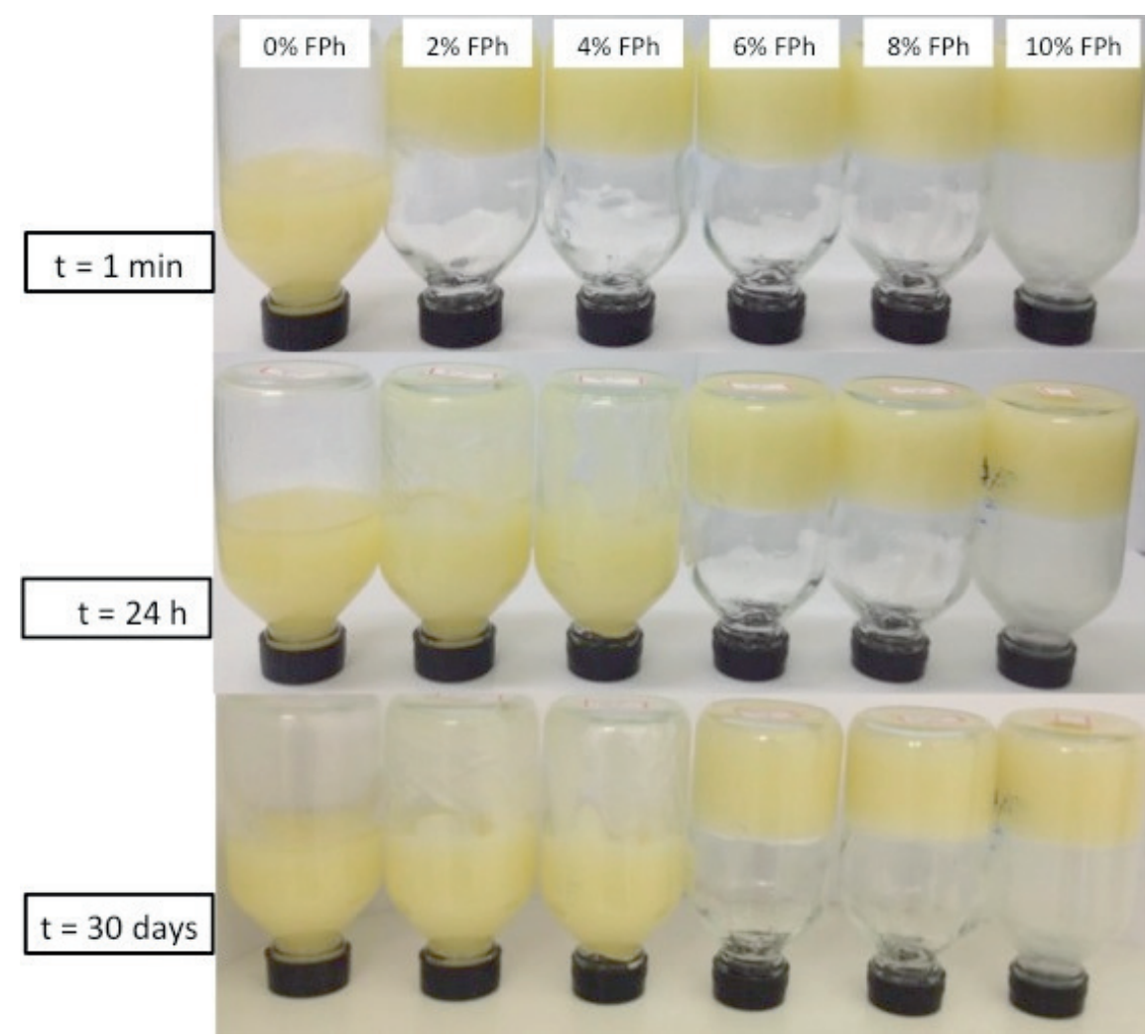

Figure 6. Images of palm oil (PO) and canola oil (CO) blends (PO:CO 50:50), added with 0, 2, 4, 6, 8, and 10\% of non-esterified phytosterols $(\mathrm{FPh})$, stabilized at $5^{\circ} \mathrm{C}$ for $24 \mathrm{~h}$ and $25^{\circ} \mathrm{C}$ for $24 \mathrm{~h}$, then inverted and exposed to oscillating room temperature (between 25 and $30^{\circ} \mathrm{C}$ ) for $1 \mathrm{~min}$, $24 \mathrm{~h}$, and 30 days

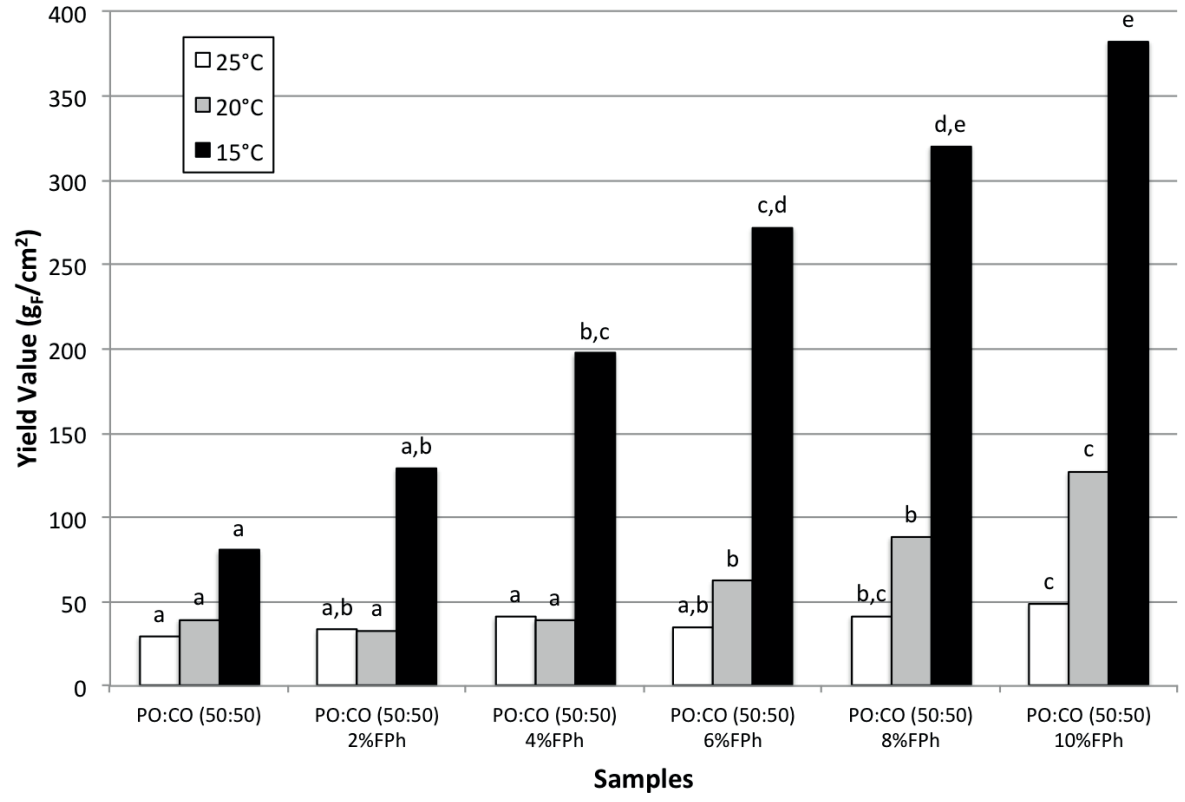

Figure 7. Yield value (in $\mathrm{g}_{\mathrm{F}} / \mathrm{cm}^{2}$ ) of palm oil and canola oil (PO:CO 50:50, in w/w\%) added with $0,2,4,6$, 8, and $10 \%$ of non-esterified phytosterols $(\mathrm{FPh})$, measured at 15,20 , and $25^{\circ} \mathrm{C}$. Same letters for the same temperature indicate that there are no significant differences between the means evaluated by Tukey's test $(p<0.05)$ 


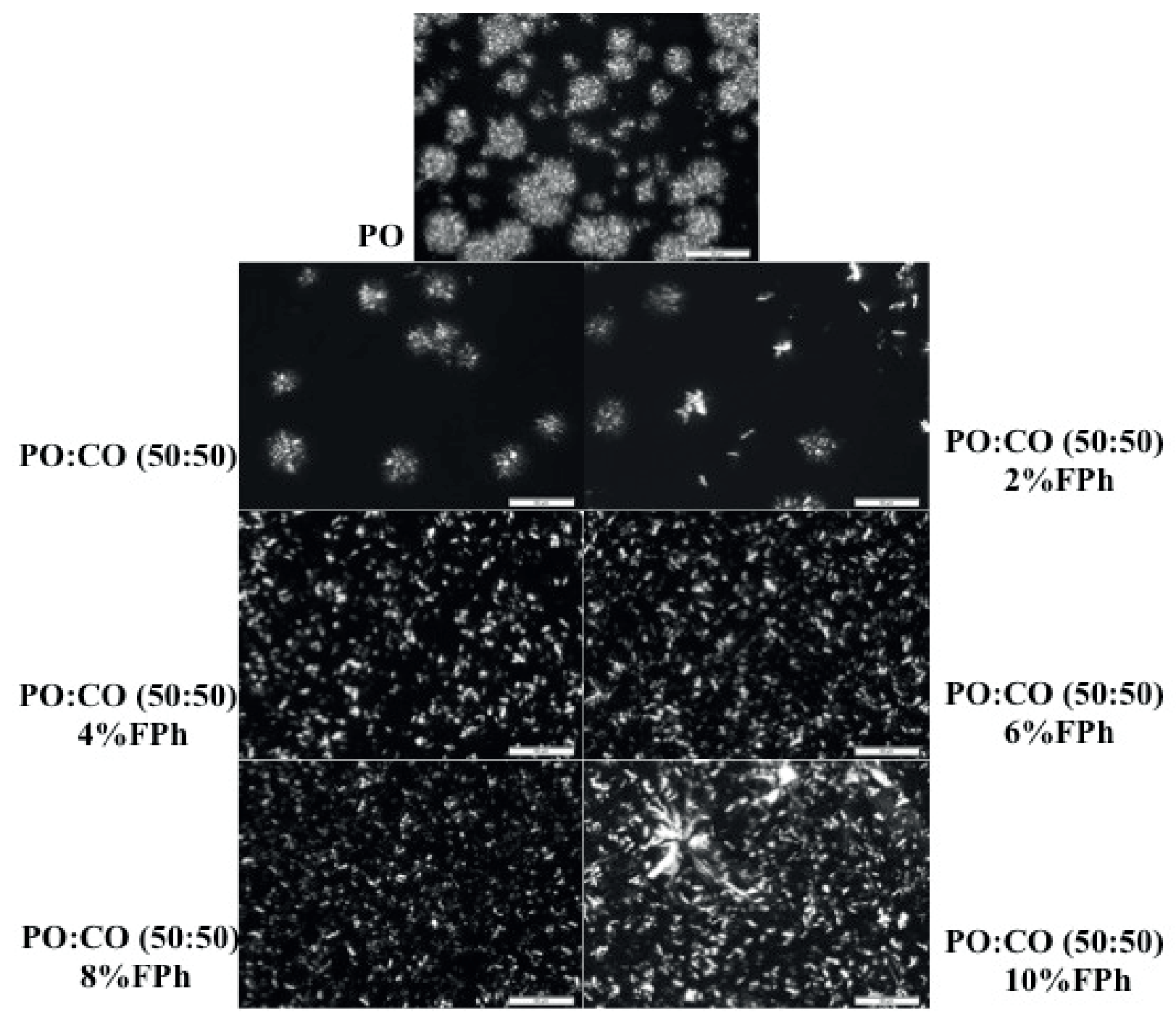

Figure 8. Polarized light microscopy images of pure palm oil (PO), and blends of palm oil and canola oil (PO:CO 50:50, in w/w\%) added with $0,2,4,6,8$, and $10 \%$ of non-esterified phytosterols ( $\mathrm{FPh}$ ), after isothermal crystallization at $25^{\circ} \mathrm{C}$, for $3 \mathrm{~h}$ (the scale bars represent $50 \mu \mathrm{m}$ )

\section{CONCLUSIONS}

Esterified and non-esterified phytosterols were evaluated as possible crystallization modifiers in palm oil. Only the non-esterified or free phytosterols form was able to effectively modify the palm oil microstructure. After chemical interesterification of the mixture containing free phytosterols in palm oil, the structuration ability of the free phytosterols disappeared probably because of their own esterification with fatty acids from palm oil. Furthermore, the structuration action of free phytosterols in palm oil and canola oil blends was evaluated and a compact fat crystal network was obtained, mainly with the addition of 6,8 , and $10 \%$ of free phytosterols. The results ratify non-esterified phytosterols as a powerful structuring agent when applied to low saturated fatty acids lipid blends.

\section{ACKNOWLEDGEMENTS}

The authors are grateful for the Brazilian financial support received from São Paulo Research Foundation (FAPESP - Proc. 2014/05365-0).

\section{REFERENCES}

Acevedo, N. C., Franchetti, D., Analysis of co-crystallized free phytosterols with triacylglycerols as a functional food ingredient. Food Research International, 85, 104-112 (2016).

Antoniosi Filho, N. R., Mendes, O. L., Lanças F. M., Computer prediction of triacylglycerol composition of vegetable oils by HRGC. Chromatographia, 40(9-10), 557-562 (1995).

AOCS. Official Methods and Recommended Practices of the American Oil Chemists' Society (5th ed.). Champaign (2009).

Basiron, Y., Palm oil - Edible oil and fats product: Chemistry, 
Properties, and health effects. Bailey's Industrial Oil and Fat Products, p. 333-425 (2005).

Belitz, H. D., Grosch, W., Schieberle, P., Lipids. In: Food Chemistry, 4th ed., Springer, Berlin, p.158-247 (2009).

Bot, A., Agterof, W. G. M., Structuring of edible oils by mixtures of $\gamma$-oryzan with beta-sitosterol or related phytosterols. Journal of the American Oil Chemists'Society, 83(6), 513521 (2006).

Bot, A., Veldhuizen, Y. S. J., den Adel, R., Roijers, E. C., Non-TAG structuring of edible oils and emulsions. Food Hydrocolloids, 23(4), 1184-1189 (2009).

Campos, R., Experimental methodology. In: Fat Crystal Networks. Ed. Marangoni, A.J., Marcel Dekker, p. 267-349 (2007).

Co, E. D., Marangoni, A. G., Organogels: An alternative edible oil-structuring method. Journal of the American Oil Chemists' Society, 89(5), 749-780 (2012).

Dassanayake, L. S. K., Kodali, D. R., Ueno, S., Formation of oleogels based on edible lipid materials. Current Opinion in Colloid and Interface Science, 16(5), 432-439 (2011).

Ferrari, R. A., Esteves, W., Mukherjee, K. D., Alteration of steryl ester content and positional distribution of fatty acids in triacylglycerols by chemical and enzymic interesterification of plant oils. Journal of the American Oil Chemists' Society, 74, 93-96 (1997).

Grimaldi, R., Gonçalves, L. A. G., Ando, M. Y., Optimization of chemical interesterification of palm oil (In Portuguese). Quimica Nova, 28, 633-636 (2005).

Haighton, A. J., The measurement of the hardness of margarine and fats with cone penetrometers. Journal of the American Oil Chemists Society, 36(8), 345-348 (1959).
Hartman, L., Lago, R. C., Rapid preparation of fatty acid methyl esters from lipids. Laboratory Practice,22(6), 475-4766 (1973).

Katan, M. B., Grundy, S. M., Jones, P., Law, M., Miettinen, T., Paoletti, R., Efficacy and safety of plant stanols and sterols in the management of blood cholesterol levels. Mayo Clinic Proceedings, 78(8),965-978 (2003).

Keys, A., Anderson, J. T., Grande, F., Serum cholesterol response to changes in the diet, IV. Particular saturated fatty acids in the diet. Metabolism, 7, 776-787 (1965).

Pernetti, M., van Malssen, K. F., Flöter, E., Bot, A., Structuring of edible oils by alternatives to crystalline fat. Current Opinion in Colloid and Interface Science, 12, 221-231 (2007).

Ract, J. N. R., Gioielli, L. A., Modified lipids obtained from milk fat, sunflower oil, and phytosterols esters for application in spreads (In Portuguese). Quimica Nova, 31, 1960-1965 (2008).

Rodrigues, J. N., Torres, R. P., Mancini-Filho, J., Gioielli, L. A. Physical and chemical properties of milkfat and phytosterol esters blends. Food Research International, 40, 748-755 (2007).

Rogers, M. A., Novel structuring strategies for unsaturated fats - Meeting the zero-trans, zero-saturated fat challenge: A review. Food Research International, 42(7), 747-753 (2009).

Siraj, N., Shabbir, M. A., Ahmad, T., Sajjad, A., Khan, M. R., Khan, M. I., Butt, M. S., Organogelators as a saturated fat replacer for structuring edible oils. International Journal of Food Properties, 18(9), 1973-1989 (2015).

Wassell, P., Young, N. W. G., Food applications of trans fatty acid substitutes. International Journal of Food Science \& Technology, 42(5), 503-517 (2007). 